\title{
The mandrill in Gabon's rain forest-ecology, distribution and status
}

\author{
Michael J. S. Harrison
}

Little is known about the mandrill Mandrillus sphinx in the wild. It is an elusive primate and thus difficult to study in its rain-forest habitat in equatorial Africa. As human pressure on its habitat grows it has become increasingly urgent to discover more about the species so that appropriate conservation measures can be planned. The author made a 15-month study of the mandrill in Gabon and discovered that it was not as widely distributed as had been believed. Although it is threatened by hunting pressure and habitat disruption, populations still remain and five reserves protect some of these.

The mandrill is a short-tailed forest baboon, well known in zoos for its startling multi-coloured face and buttocks, but relatively unknown in its natural habitat, a restricted block of tropical rain forest in equatorial west Africa. There are few published accounts of the mandrill Mandrillus sphinx in the wild, or of its nearest relative the drill Mandrillus leucophaeus (some authors regard both species as members of the genus Papio). These are reports from early zoological expeditions to equatorial Africa (e.g. Jeannin, 1936; Malbrant and Maclatchy, 1949), and later attempts at more systematic study (Gartlan, 1970; Sabater Pi, 1972; Jouventin, 1975). Frustrated by the surprisingly elusive nature of such large terrestrial primates, these studies provide limited conclusions from few observations. With increasing pressure on rain-forest habitats throughout west and central Africa, we urgently need to know more about the biology of their animal inhabitants. What, then, is the status of the mandrill in the wild, what is its distribution, and the basic elements of its ecology in one of the world's richest, most complex, and most threatened ecosystems-Africa's equatorial rain forest?

In November 1982 I attempted to examine some of these questions in a systematic study of the mandrill in Gabon, using radio-telemetry to 218 study ecology and behaviour, and various census techniques and interviews with hunters to determine densities and distributional limits. Many goals were thwarted by the lack of success at finding mandrills - a single observation of a social group in an initial 6 months of survey and census: there was indeed good reason why these animals were so little known. The radio-tracking study proved impossible, but extensive surveys were conducted, and 10 further contacts were made during the following 9 months. Over this 15-month period, some new and pertinent information on the distribution, ecology, population density and conservational status of the mandrill was recorded, and is reported here.

\section{Distribution}

Drills and mandrills live in rain forest from eastern Nigeria to southern Congo (Figure 1). The two species were formerly considered to be sympatric (e.g. Malbrant and Maclatchy, 1949), an impression that still persists in some contemporary reviews (e.g. Haltenorth and Diller, 1977) where drills and mandrills are said to occur together through much of their range. However, Grubb (1973) critically examined museum records and concluded that the Sanaga River in Cameroon divides the two species, the drill to the north (and on Bioko/Fernando Poo), the mandrill to

Oryx Vol 22 No 4, October 1988 


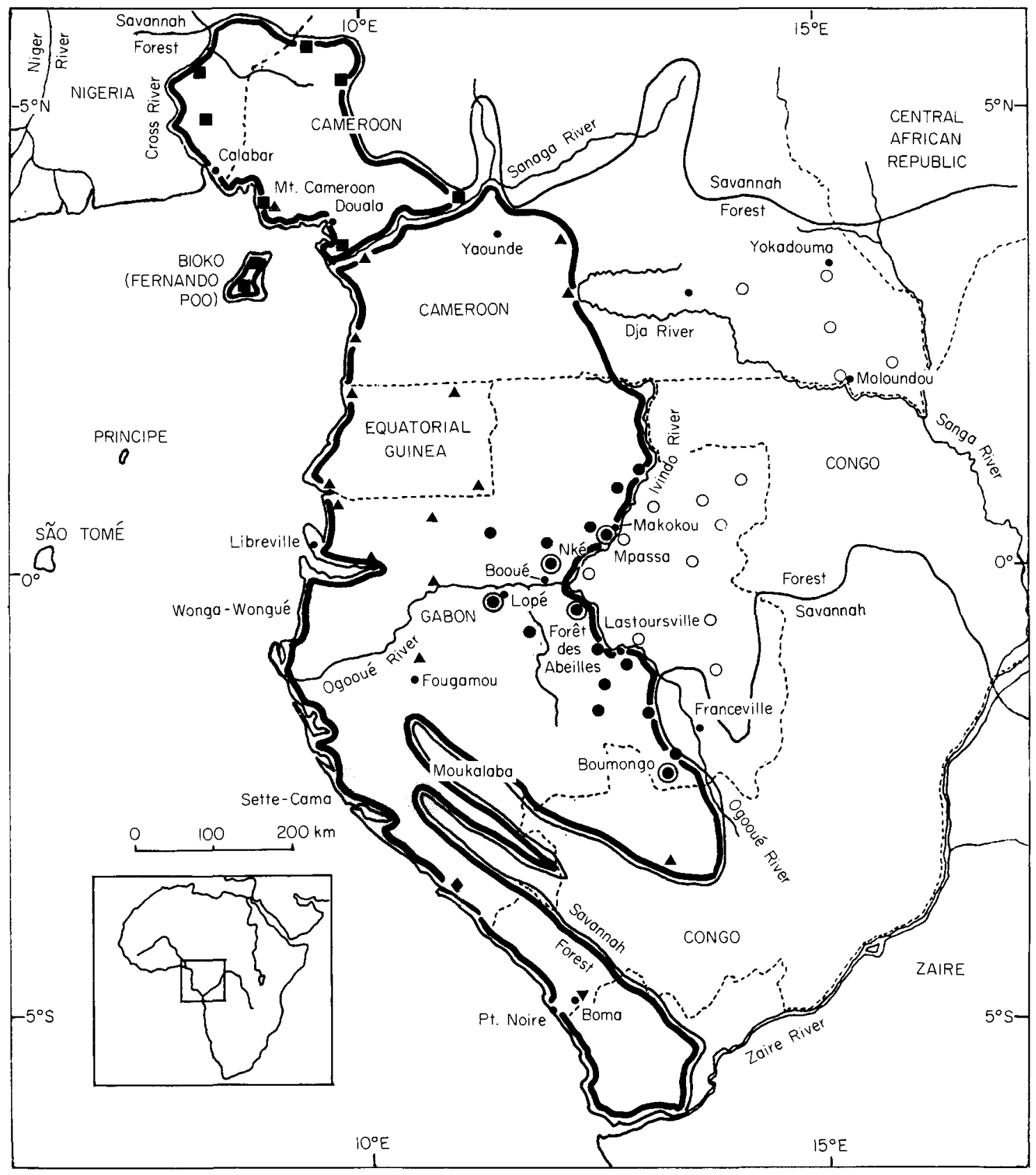

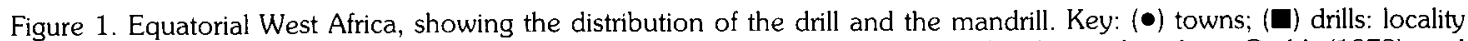
of museum specimens; ( $\boldsymbol{\Delta}$ ) mandrills: locality of museum specimens-museum localities taken from Grubb (1973), and only geographical extreme points given for each country; (O) mandrills present $(\mathrm{MH}$ interviews and observations); (O) mandrills absent (MH interviews); ( $\mathbf{\nabla})$ mandrill locality given by Bassus (1975, in Wolfheim, 1983) and Congolese hunter $(\mathrm{MH}) ;(1)$ mandrill observation by Tutin and Fernandez (pers. comm.); (O) mandrill census site. The thick black line shows the overall distribution of drills to the north, and mandrills south, of the Sanaga River. Shaded areas are faunal reserves within Gabon.

Mandrill in Gabon's rain forest 
the south, and nowhere do they occur together. Most evidence to the contrary appears erroneous: museum specimens have been misidentified or their localities confused; field reports have not been substantiated. Although Malbrant and Maclatchy (1949) cited a number of localities in Gabon where drills were to be found, and even listed measurements of a specimen adult male drill from Fougamou (see Figure 1) in western Gabon, they did not state whether they had personally examined this specimen, nor are their claims that drills are common elsewhere in Gabon backed by photographs or museum specimens.

I occasionally heard reports of drills in Gabon, but these were almost certainly confusions with immature or adult female mandrills, which like drills lack the bright and full facial colours of older male mandrills. Recently there was a published report of an observation of drills in the Lopé Reserve in central Gabon (Nicoll and Langrand, 1986), but due to the ease of confusion of younger animals of the two species in dim forest light, this observation needs to be confirmed with an animal in the hand. Most of the evidence suggests that the drill does not occur in Gabon, and its absence from Equatorial Guinea also seems well established by extensive local reports (Sabater $\mathrm{Pi}, 1972$ ). The ecological similarity of drills and mandrills further suggests that they are unlikely to live sympatrically. Before dismissing it completely, however, we should bear in mind our ignorance of the distribution of many mammals throughout the rain forests of central Africa, which was recently accentuated by the discovery of a new species of guenon in central Gabon (Cercopithecus solatus; Harrison, 1988).

South of the Sanaga River, mandrills occur in western Cameroon and throughout Equatorial Guinea (Sabater Pi, 1972; Grubb, 1973; Figure 1). After two years spent recently with Baka pygmies in south-east Cameroon (throughout the forest from Lomié-Yokadouma-Mouloundou: approximately $2^{\circ} 00^{\prime}-3^{\circ} 30^{\prime} \mathrm{N}$ and $14^{\circ} 30^{\prime}$ $\left.16^{\circ} 00^{\prime} \mathrm{E}\right)$, I found no evidence of the mandrill. After extensive zoological collection here and in northern Congo, Merfield and Powell-Cotton found no evidence of the mandrill either (Grubb, 220
1973). It seems to be limited to western forests, possibly west of the Dja River where the floristic composition of the forest changes.

Further south, in Gabon, the mandrill has been reported as occurring throughout the country and eastwards into Congo, with question marks abouts its eastern limits, ever since Malbrant and Maclatchy's blanket statements about its distribution. During my surveys, I interviewed hunters throughout eastern Gabon, at locations marked on the map (Figure 1). Results of these interviews show the distribution of the mandrill to be much more restricted than previously assumed. The Ivindo and Ogooué Rivers form the eastern limits of distribution, confirming their absence from northern Congo, but also establishing their absence from the entire eastern third of Gabon itself. Indeed, in Makokou the mandrill was locally called le diable des Fang, the devil of the Fan, who are a dominant ethnic group in northern Gabon that migrated southwards and eastwards from Cameroon but whose limit is also the Ivindo River.

To the south, I had one report from a reliable Congolese hunter of mandrills near his home at Boma in southern Congo. He described them as very rare because of heavy hunting. Bassus (1975, cited in Wolfheim, 1983) also reported mandrills in the Niari valley, near Boma. Malbrant and Maclatchy (1949) reported mandrills at the mouth of the Zaire River. Distribution is likely to be limited by savannah zones to the east, and by the Zaire River to the south.

\section{Ecology}

From my own observations and those of Jouventin (1975), and more recently Hoshino et al. (1984) and Lahm (1986), the broad features of the ecology of mandrills can be outlined. Work was conducted in the north-east (Makokou) and central (Booué) areas of Gabon. In addition I searched near Lastoursville and Franceville towards the south-east, as well as interviewing hunters in the eastern block of the country, and making some observations on a captive colony kept in a forested enclosure at the Centre Internationale de Recherche Medicale de Franceville (CIRMF). Jouventin, working in the same areas Oryx Vol 22 No 4, October 1988 
of Makokou and Booué, had made 39 contacts with mandrills in 6 months, while I made only four, three with solitary adult males and one with a large group. In a subsequent 9 months in the Lopé Reserve in central Gabon (near Booué), while studying the ecology of the black colobus Colobus satanas, I made 10 further contacts with mandrills. While such infrequent contact makes systematic study impossible, it certainly emphasizes the scarcity of these animals and the need for a rational assessment of their conservation status.

\section{Habitat}

The preferred habitat of mandrills is primary rain forest, although they do use secondary forest, often near villages where plantations are raided. It is unlikely that mandrills penetrate savannah areas far (e.g. by following gallery forest along streambeds), although they do cross grassland areas within the primary forest. A predominantly terrestrial primate, the mandrill is most commonly found in the ground- or lower-level vegetation, but does feed at any level, including the high canopy.

\section{Diet}

The diet is mainly frugivorous but highly diverse, including fruit, seeds, arils, young leaves, pith, flowers, roots, fungi, invertebrates and (rarely) vertebrates. Although fruit forms a major part of the diet, vegetable and insect components seem essential in the mandrill's nutritive balance. Lahm (1986) found a predominance of fruit in a limited number of stomach contents and faeces, and common insect remains. Feeding remains left by mandrills showed that they also ate herbaceous vegetation on the forest floor, notably young leaf petioles of the Marantaceae (arrowroots) and pith from stems of the Zingiberaceae (gingers). In the stomach of one snared juvenile mandrill, I found 13 per cent dry weight of clay (the remaining 87 per cent was roots and vegetable fibres mixed with insect wings and legs). Unless the clay was deliberately eaten, perhaps for minerals or as a toxin-absorbant, it was probably ingested with the thin fibrous roots that were common. Mandrills in the captive colony at CIRMF were frequently observed to dig for and Mandrill in Gabon's rain forest

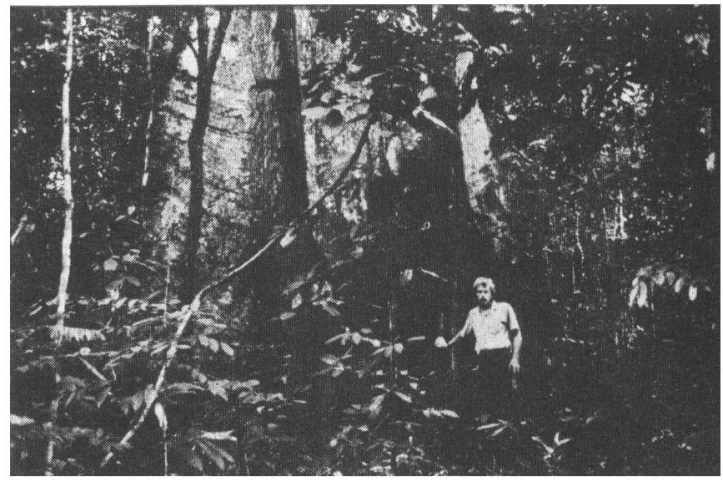

The base of a forest giant Ceiba pentandra in relatively open forest (Michael Harrison).

eat shallow roots and rhizomes. This shows a strong behavioural link with baboons (Papio and Theropithecus) elsewhere in Africa, who dig for roots and rhizomes in certain seasons. It also suggests an overlap with the niche of other forest-floor mammals such as bushpigs Potamochoerus porcus.

There were several independent reports from hunters of mandrills eating duikers Cephalophus spp.) and fledgling birds and eggs; Kudo and Mitani (1985) described the predation of a juvenile bay duiker Cephalophus dorsalis by mandrills in Cameroon; Jouventin (1975) had reports of frogs, lizards, fish, shrimps and crabs being eaten, and Lahm (1986) found remains of a number of rodents in stomach contents and faeces.

\section{Ranging}

We known even less about the ranging patterns of mandrills than we do of their diet. Jouventin (1975) has suggested distances of $5-15 \mathrm{~km}$ travelled daily (one group was followed $8 \mathrm{~km}$ in one 24-hour period), and home-range areas of $40-50 \mathrm{sq} \mathrm{km}$ (one large group in an area of $10 \times 5 \mathrm{~km}$ delimited on three sides by rivers). My experience in Gabon indicates that such estimates may not be unreasonable: while studying black colobus in the Lopé Reserve, with regular visual or auditory coverage of one area of 4-5 sq $\mathrm{km}$, I made 10 contacts with mandrills in groups of up to 200 during 5 weeks in AugustSeptember 1983, but no further contacts during another 8 months in the same area. If we conclude from this that mandrills use all areas of their 


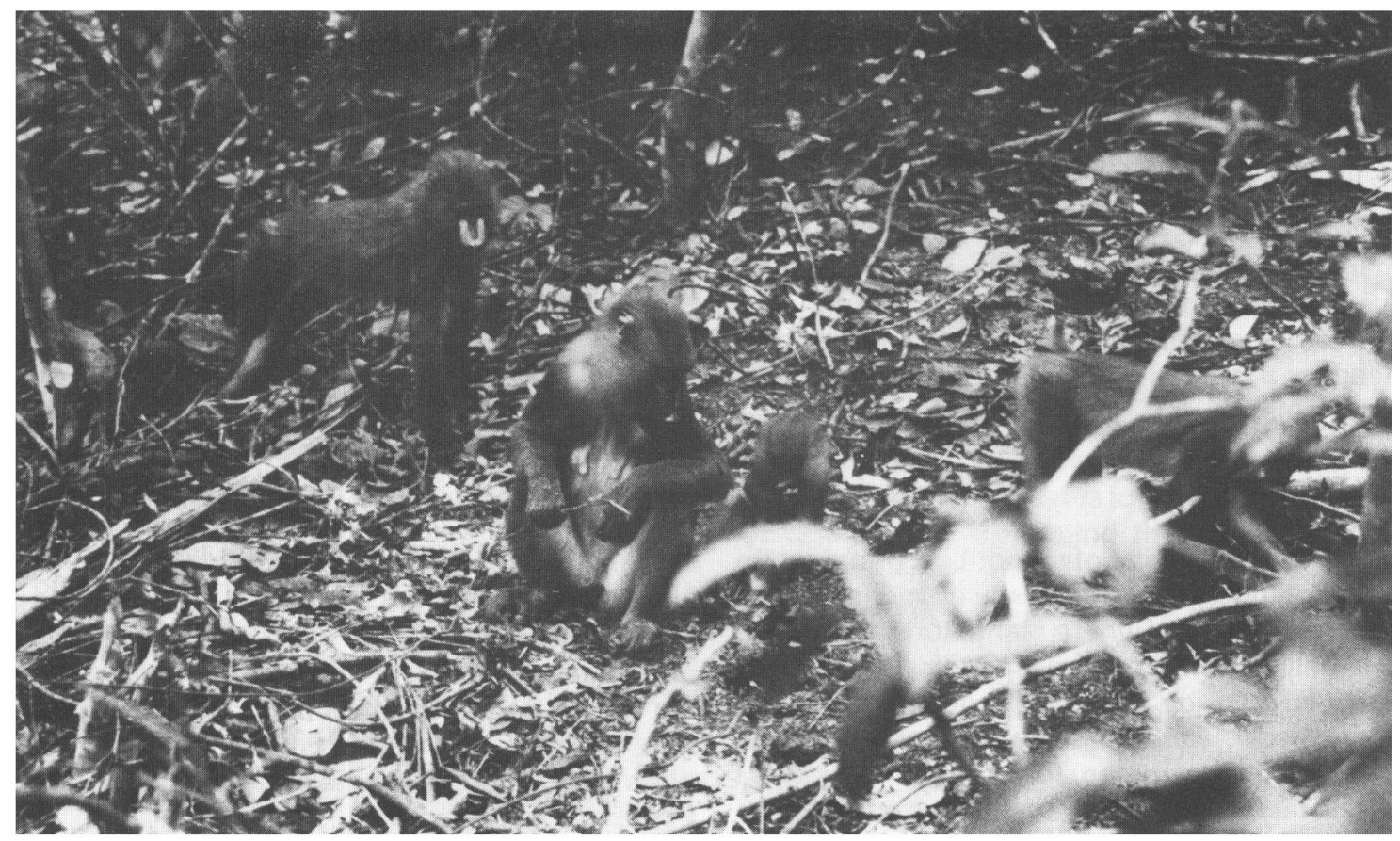

Part of a group of mandrills foraging for insects and roots on the forest floor. The female in the foreground is about to eat a root (E. Rogers).

range on a seasonally shifting basis, 1 month in 4-5 sq km suggests a range over 9 months of 36-45 sq km. Hoshino et al. (1984) estimated that the range of a group of 95 mandrills might reach $30 \mathrm{sq} \mathrm{km}$ in southern Cameroon. If mandrills use the forest more selectively, concentrating more time in particular areas, such estimates should be revised downwards.

These are enormous ranges, considering the richness of potential resources in primary tropical rain forest. However, mandrills live in very large groups (see below), and by considering their biomass these large ranges are put into perspective: adult females weigh $10-15 \mathrm{~kg}$, while large males weigh up to $30 \mathrm{~kg}$. Using Hoshino's estimates of group composition ( 7 per cent adult males, 43 per cent females and younger males, 50 per cent juveniles and infants), a very rough estimate of the biomass of 200 mandrills in $40 \mathrm{sq} \mathrm{km}$ of forest is $50 \mathrm{~kg}$ per sq $\mathrm{km}$. This is not greatly different from the biomass of other frugivorous cercopithecines in Gabon, estimated at $30-110 \mathrm{~kg}$ per sq $\mathrm{km}$, in ranging 222 areas of 1-2 sq km (Table 1; and in Harrison and Hladik, 1986).

\section{Social organization}

Social groupings of mandrills (and possibly drills) are the most variable of any rain-forest primate, varying in size from small groups of 15 individuals to large aggregations of 250 or more. The largest aggregation to have been recorded was a group of at least 344 in the Lopé Reserve in central Gabon (C. Tutin, pers. comm.). Our observations suggest that these large groupings are aggregations of smaller groups that may associate, or feed and travel separately. These groups appear to be one-male units, or extended harems, and are likely to be basic social units. Counts in Jouventin's 28 observations of social groups have a bimodal distribution: 13 groups of $20-50$ animals, and 10 aggregations of over 175 animals. The median size of one-male units was 29 , and the median size of large aggregations was 175 (calculated from Table 4 in Jouventin, 1975). Seven recent group counts from the Lopé Oryx Vol 22 No 4, October 1988 
were as follows: $344,328,225,225,214,184$, 130 (Tutin and Fernandez, unpublished project results). In the latter four counts, there were 2732 individuals per fully adult male.

Some observations may illustrate this social flexibility. In the Lopé Reserve (March 1983), I followed for half the day a small silent group of 40 mandrills, amongst whom only one adult male was seen. This unit was feeding and moving independently of any large group. Hoshino et al. (1984) followed an independent unit of 15 mandrills for 5 days without meeting other mandrills. Such units were observed on several occasions to result from larger groups, splitting up, or to become part of larger groups forming as several subgroups joined. Even within large aggregations, subgroupings are persistent. For example, I observed a noisy group of over 150 mandrills in the Lopé Reserve (September 1983), in which a number of subgroups were spread over $500 \mathrm{~m}$, moving in a swathe both on the ground and in fruiting trees. Each group formed a cohesive unit, maintaining contact with other units by a continuous chorus of two-phase contact barks, grunts, and 'crowing' calls. I counted one subgroup of 52 emerging from a single feeding tree. This subgroup contained four large males, of whom three were young and not fully mature, while only one was obviously fully mature, larger and full-bodied, his spectacular colouring well developed: electric blue ridged cheeks, vivid red

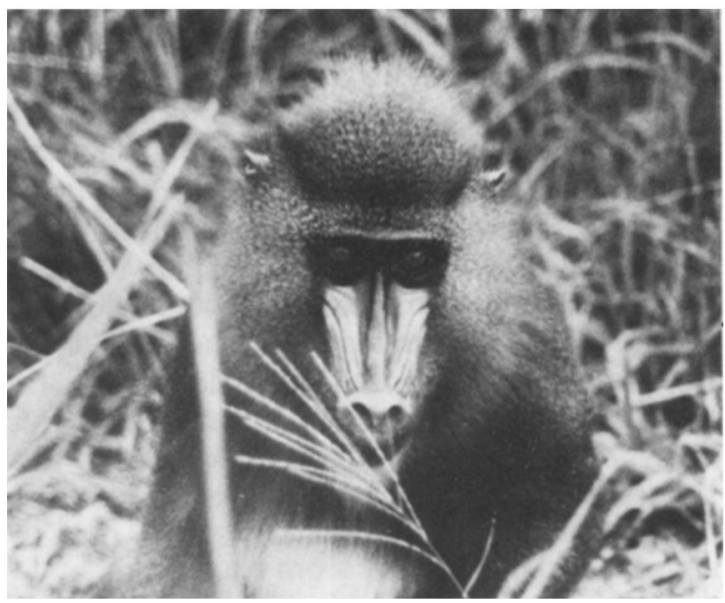

An adult female mandrill, showing the cheek ridges (Michael Harrison).

nose, extensive golden beard, and broad pink and mauve haunches. This may indicate some form of age-graded 'extended harem' unit.

These observations suggest that there are several levels of social organization, from a basic onemale unit to very large aggregations with a number of adult males present. Possibly there is an intermediate level of relationship between sets of units, or extended units still containing only one prime adult male but including also several younger adult males. In some respects, this parallels the social systems of hamadryas Papio

Table 1. Relative abundance of primates in Gabon

\begin{tabular}{|c|c|c|c|c|c|}
\hline & \multirow{2}{*}{$\begin{array}{l}\text { Approximate } \\
\text { group size }\end{array}$} & \multirow{2}{*}{$\begin{array}{l}\text { Individuals } \\
\text { persq km }\end{array}$} & \multicolumn{2}{|c|}{ Body weight } & \multirow{2}{*}{$\begin{array}{l}\text { Biomass } \\
\mathrm{kg} / \mathrm{km}^{2}\end{array}$} \\
\hline & & & Male & Female & \\
\hline Gorilla gorilla & $(1-19)^{*}$ & 0.18 & $140-200$ & $70-110$ & 15 \\
\hline Pan troglodytes & $(1-10)^{*}$ & 0.32 & $40-55$ & $30-50$ & 10 \\
\hline Colobus satanas & $9-15$ & $20-40$ & $10-12$ & $8-11$ & $150-300$ \\
\hline Miopithecus talapoin & $65-110$ & $40-90$ & $1.2-1.9$ & $0.8-1.2$ & $40-80$ \\
\hline Cercopithecus nictitans & $13-28$ & $20-40$ & $6-8$ & $3-4$ & $80-110$ \\
\hline C. cephus & $10-15$ & $20-30$ & $4-5$ & $3-4$ & $70-80$ \\
\hline C. pogonias & $13-20$ & $20-30$ & $3-6$ & $2-3$ & $60-70$ \\
\hline C. neglectus & $3-6$ & $30-40$ & $5-8$ & $4-5$ & $90-110$ \\
\hline Cercocebus albigena & $10-20$ & $10-20$ & $6-11$ & $4-7$ & $50-110$ \\
\hline Cercocebus galeritus & $10-18$ & $8-12$ & $7-13$ & $5-7$ & $30-50$ \\
\hline Mandrillus sphinx & $175-250$ & $5-7$ & $20-30$ & $10-15$ & 50 \\
\hline
\end{tabular}

Data from Gautier and Gautier-Hion (1969), Gautier-Hion and Gautier (1974), Harrison (unpub. data), Jouventin (1975), Tutin and Fernandez (1984), and this study. *Nest group size. 
hamadryas and gelada Theropithecus gelada baboons in dry savannah and alpine grassland in north-east Africa, and pig-tailed macaques Macaca nemestrina in Malaysian rain forest.

As young males mature, they apparently leave social groups and live alone. I saw both subadult and fully mature solitary males, but never a group of males together, although two fully adult males have been seen together, on their own ( $E$. Rogers, pers. comm.). One old male was seen on two occasions 17 days apart, with a wound on his thigh apparently from a canine slash. This suggests that old males may be excluded from social groups following conflicts.

The importance of communication in maintaining contact between individuals or units in these complex social mixings is paramount, and has led to an extraordinary array of calls, and to the colour patterns on face and buttocks, which are probably important visual signals in the dark forest understorey. These colour patterns are particularly striking and well developed as secondary sexual characteristics of prime adult males, but are more subdued in younger adults and females, and virtually absent in juvenilesexcept for the golden beard.

A thriving, reproducing colony of mandrills exists in a forested enclosure at CIRMF in Gabon, where studies of some of the details of social behaviour are under way.

\section{Predators}

People are undoubtedly the current major predator of mandrills. Natural predators are probably limited to the leopard Panthera pardus, the crowned eagle Stephanoaetus coronatus, and potentially the chimpanzee Pan troglodytes and some of the snakes, Bitis, Python. In March 1983 in the Lopé Reserve, I was following a group of some 40 individuals as they picked through the leaf litter in dense undergrowth that covered steep ravines, when they flushed a leopard from a small cave. The mandrills exploded into a confusion of scattering and screaming; most climbed into the lower canopy while keeping visual track of the leopard as he walked calmly away (towards me), others fled on the ground. The 224 leopard bolted on seeing me. The response of the mandrills was clearly one of fear towards a predator. On another occasion, I found a juvenile mandrill that had been caught in a hunter's snare but subsequently killed by a crowned eagle, which flew off from the corpse as I approached. Jouventin too found crowned eagle feathers at the site of a mandrill kill, and has seen a leopard feeding on the remains of a mandrill.

\section{Competitors and other mammals}

There is a very rich primate fauna sharing the forest with mandrills. There are 14 simian species in Gabon (Table 2), of which only two (the crested mangabey and the black-and-white colobus) occur outside the distribution of the mandrill, in north-east Gabon. These potential food competitors all show adaptations to specific niches that reduce competition and allow many species with superficially similar diets to inhabit the same forest. The talapoin and de Brazza's monkey favour inundated forest, the spot-nosed, moustached, and crowned guenons and the grey-cheeked mangabey are all strictly arboreal, the black colobus is a specialist seed-eater; all these habits and preferences differ from those of the mandrill. Two cercopithecine monkeys that are partly terrestrial, and may have a more similar diet to the mandrill, are the collared mangabey, which is limited in distribution to forests along the Atlantic coast, and the newly discovered sun-tailed monkey, which has a very restricted range in central Gabon. The chimpanzee and the gorilla are more widespread and use similar habitat and foods to the mandrill, but have different ranging patterns, social structure, and specific food preferences.

On a number of occasions solitary mandrills were seen with other primates (spot-nosed, moustached and crowned guenons, and greycheeked mangabeys), the mandrill foraging on the ground beneath the arboreal monkeys, possibly on food items dislodged by those above. Although polyspecific associations among the arboreal cercopithecines are common in rain forest, no such multi-species groups were seen involving a social group of mandrills. Other mammals whose niches overlap with mandrills, 
Table 2. Fourteen species of simian primates in Gabon

\begin{tabular}{ll}
\hline Talapoin & Miopithecus talapoin \\
Guenons: & Cercopithecus nictitans \\
Spot-nosed & C. cephus \\
Moustached & C. pogonias \\
Crowned & C. neglectus \\
De Brazza's & C. solatus \\
Sun-tailed & Cercocebus galeritus \\
Mangabeys: & C. albigena \\
Crested & C. torquatus \\
Grey-cheeked & Colobus satanas \\
Collared & C. guereza \\
Colobus: & Mandrillus sphinx \\
Black & Pan troglodytes \\
Black-and-white & Gorillagorilla \\
Mandrill & \\
Chimpanzee & \\
Gorilla &
\end{tabular}

and where there may be some feeding competition, include the frugivorous ground-foraging duikers and the bush-pig.

\section{Population density}

The geographical distribution of the mandrill in Gabon has been shown to be more restricted than previously thought, although this is the country that undoubtedly has the greatest remaining population of mandrills. Estimation of the size of the population is very difficult, given dense habitat and elusive, wide-ranging animals. I carried out systematic censuses at five sites in different areas of the mandrill's range in Gabon (Figure 1), using transect-line censusing methods. At three sites (Makokou, Nké, Lopé) 5-km transect lines were set up and walked along repeatedly, up to a maximum of 17 times; at two other sites (Boumongo, Forêt des Abeilles) measured trails were walked opportunistically. Sites at Makokou and Lopé were within areas officially protected from hunting, although in practice this was not always the case at Makokou. Nké and Boumongo were logged forests, where hunting did occur, but the site in the Forêt des Abeilles was remote and hunting was rare.

The total transect length walked was $313.4 \mathrm{~km}$, with an estimated strip-width of $100 \mathrm{~m}(50 \mathrm{~m}$ visibility either side of the transect line), giving a sampled area of $313.4 \times 0.1=31.3 \mathrm{sq} \mathrm{km}$. During these transects only one group of man- drills was observed, which results in an estimated population density of 0.03 groups per sq $\mathrm{km}$, or one group per $31 \mathrm{sq} \mathrm{km}$. The limitations of this estimate must immediately be stressed: based on such a low contact rate, this method is unreliable without greatly increasing transect length. Data cannot be treated meaningfully from each of the five transect sites separately. The very low density allows no control for habitat type in the analysis, for pristine $v$. degraded forest, for hunted $v$. protected areas. Censusing is complicated by the fission and fusion of small groups and large noisy aggregations of mandrills, although small groups would be more numerous, and large groups more 'visible', so biases might tend to cancel out. And lastly, the assumption of a 100-m strip-width to calculate sampled area takes no account of the highly vocal habits of mandrills, which means that effectively a far greater area is sampled by ear for the presence of mandrills than that calculated using visible strip-width. My contacts with mandrills outside systematic censuses were generally made following auditory locations of groups up to $1 \mathrm{~km}$ away.

The best we can conclude is that population density in the areas surveyed is likely to be no greater than 0.03 large groups of mandrills per sq $\mathrm{km}$, and probably less. The estimate compares favourably with estimates of home-ranges (above) of 30-50 sq km.

\section{Conservation}

\section{Résumé of ecology}

However limited, our understanding of the mandrill's ecological and social adaptations to the rain forest is important in any discussion of conservation issues. Mandrills must exploit a forest with a patchwork of unevenly dispersed and seasonally changing food sources. The distribution and fruiting patterns of rain-forest plants are highly complex: some rely on wind for seed dispersal, others rely on transport by frugivorous birds and mammals; some large isolated trees produce an abundant but localized fruit crop, while smaller trees and herbaceous plants are more common but less productive; some species produce fruit in synchrony, whereas others fruit individually throughout a season. 
As a large-bodied, semi-terrestrial member of the rain-forest's community of frugivores, the mandrill's solution has been to forage over wide areas for a diverse diet, adopting a flexible social organization that allows small socially stable groups to forage independently or to unite into large aggregations, according to the distribution and abundance of food. Large seasonal shifts in ranging would allow access to food plants with sporadic distribution or asynchronous fruiting, or to areas of forest with different plant communities.

Seasonal patterns in mandrill groupings were found by both Jouventin (1975) and Hoshino et al. (1984): small groups of mandrills were more common in the major fruiting season, while larger groups were more common in the minor fruiting season. If fruit crops in the major fruiting season are distributed in abundant but localized

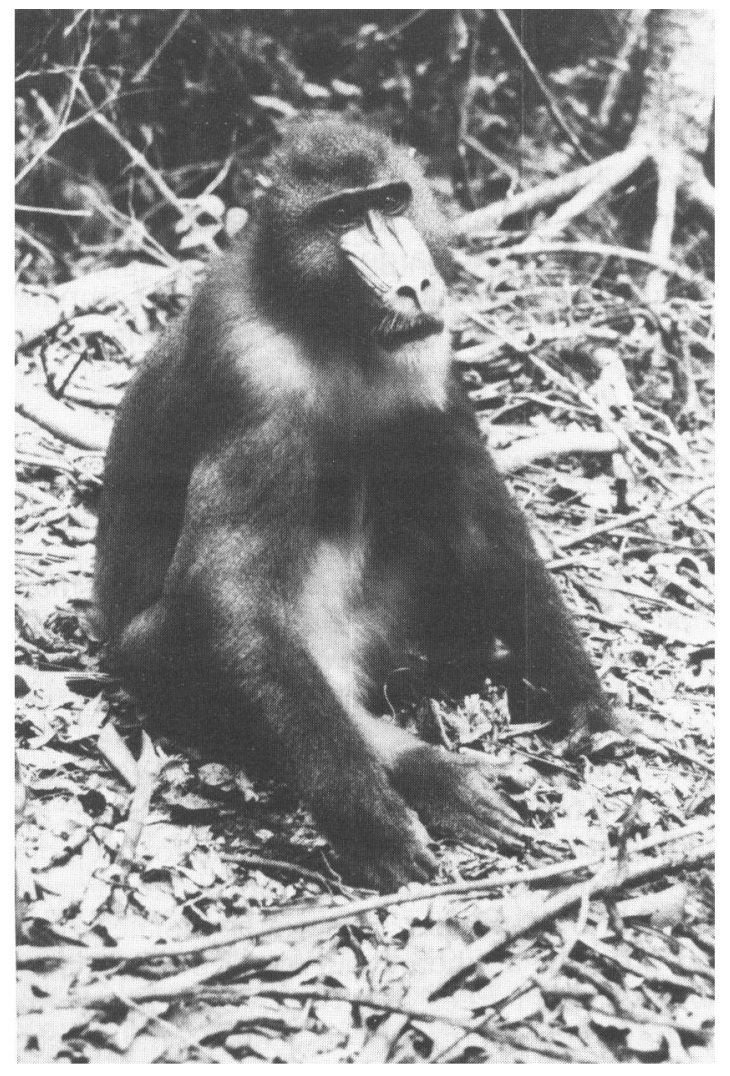

A sub-adult male mandrill (E. Rogers). patches, smaller units of mandrills may forage more successfully than large groups. Conversely, outside the major fruiting season, foliage and herbaceous plants become more important in the diet, and can be exploited successfully by large aggregations of mandrills because these foods are widely and evenly dispersed.

The resulting wide-ranging habits of the mandrill give it an important role in the dynamics of the rain forest, as an agent of long-distance seed dispersal. In this respect, it is matched only by the importance of the forest elephant Loxodonta cyclotis and the chimpanzee. The patterns of use of the forest by these species, in particular their apparently seasonal shifts in range, suggests that they are among the first to suffer from habitat disruption. These factors have important implications for conservation policy, for example when considering minimum critical sizes of areas to be protected.

The presence of large groups of mandrills is likely to reflect a relatively healthy forest, but there is strong evidence to suggest that large frugivores are among the first species to be endangered by habitat disturbance in rain forest (Johns and Skorupa, 1987). The result in this case will be a long-term imbalance as an important element in forest dynamics is removed.

An additional consideration is that the mandrill is a striking example of the regional endemism that characterizes the rain forest in this part of West Africa. Many species of forest mammals have restricted distributions here, reflecting radiation from a forest refuge in coastal Cameroon and Gabon during the last ice age. The mandrill is part of the unique genetic pool that is held in West African rain forests.

\section{Population size}

The earlier estimate of population density cannot be used to estimate the size of the mandrill population throughout the country. In order to extrapolate from the area of distribution, we need more accurate data on densities in different habitats with different degrees of disturbance from hunting, forestry or development. In areas that are inhabited by farming people and where forest has been depleted, mandrills are ex- 


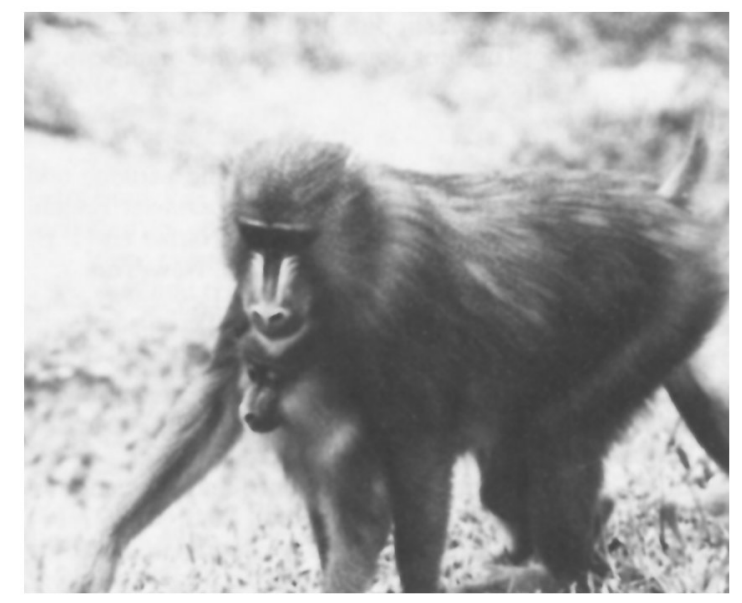

An adult female mandrill with an infant (Michael Harrison).

tremely rare or have been eliminated. Overall numbers have undoubtedly declined in recent years, not through an increase in human population, which is expanding slowly in Gabon, but due to the increasing availability of shotguns and transport, and accessibility to previously isolated areas of forest: compare Jouventin's observation rate of six or seven sightings of mandrills per month (1975), with my own 10 years later of less than one sighting per month, over a period of 15 months in the forest. This probably reflects a combination of factors, including reduced numbers, greater wariness towards people, and (given the wide-ranging habits of mandrills), reduced use of forest easily accessible by people.

A useful indicator of the status of the mandrill population, from the limited data available, is provided by comparison with the relative abundance of other primates. An estimate of mandrill density is calculated from 0.03 groups per sq $\mathrm{km}$, using 175-250 as group size (the median size of large aggregations counted by Jouventin, to the largest group he counted more than once). This gives a density of five to seven individuals per sq $\mathrm{km}$. Table 1 summarizes the available data from various areas of Gabon and shows that, apart from the great apes, mandrills occur at the lowest density, despite their extremely large group sizes.

\section{Threats to survival}

Threats to the survival of mandrills come from Mandrill in Gabon's rain forest hunting pressure and habitat disruption, pressures that are by no means exclusive to mandrills. Mandrill meat is highly prized locally, but due to their elusiveness, hunting for mandrills is not systematic; indeed this is the case for most terrestrial forest mammals, since the common practice of using ground snares is largely opportunistic. When hunted with dogs and guns, however, hunters report that the characteristic response of mandrills is to flee from the dogs into the canopy; once in the canopy their limited mobility makes them relatively easy targets for shotguns.

Forestry exploitation poses another threat to the mandrill, as it does to much forest flora and fauna. Such blanket statements are not useful, however, unless a greater understanding of the processes involved is developed. Forestry practices in much of this area of the Congo forest bloc are selective, and relatively few species are sought. In some cases less than one tree per hectare is exploited, although this does not take account of damage during exploitation, such as road construction and wastage. Much work has been done in South East Asia on the effects of logging on primate populations (see review in Johns and Skorupa, 1987), but very little in Africa (Skorupa, 1986), with its particular types of forest and patterns of exploitation. The degrees of short-term disturbance and long-term damage to animal populations and forest dynamics in African rain forest urgently needs to be studied. However, what is clear immediately is that selective logging per se is less of a threat to forest fauna than its indirect consequences: the opening of virgin areas of forest to an influx of forestry workers, hunters, and settlers, who with snares and guns can very rapidly deplete animal populations.

\section{Conservation measures}

The mandrill is to be included in the forthcoming Red Data Book on mammals, the International Union for Conservation of Nature and Natural Resources listing of endangered species, and Gabon has very recently (December 1987) become a signatory to CITES, the Convention on International Trade in Endangered Species of Wild Fauna and Flora. But, at present, the mandrill has no legal protection within Gabon, except 
where populations exist in reserves. There are five such reserves (Wonga-Wongué, Lopé, Moukalaba, Sette-Cama, Mpassa-Makokou), of which one, the Lopé has been proposed as Gabon's first national park. Currently its status is that of a Réserve Integrale de Faune et de Flore, where both fauna and flora are protected; however, logging continues within the Lopé Reserve, and forestry permits are not being revoked.

It should be emphasized that the species distributions given in Figure 1, for both mandrills and drills, are very optimistic. These animals are by no means found throughout the areas delineated. Where there is high human population density, in extensive areas around cities, major towns and cultivated land, few animals survive, and in much of eastern Nigeria, eastern and southern Cameroon, Equatorial Guinea, and coastal Gabon, animal populations survive only in increasingly isolated pockets. Only in central and north-eastern Gabon are there extensive tracts of unpopulated rain forest where mandrills still occur.

The conservation of mandrills cannot be considered in isolation from the conservation of intact habitats, with an integrated, natural range of fauna and flora. In the long term, rational management of rain forests must consist of a balance between biological interests on the one hand, and economic and social interests on the other hand, through policies that encourage sustainable development of forest resources in some areas, and complete protection of intact flora and fauna in other areas.

The establishment and maintenance of protected areas in Gabon already has a well-established infrastructure in the Ministère des Eaux et Forêts, and, as a first step, the creation of the Parc National de la Lopé in central Gabon would be an encouraging stamp of Gabon's commitment to this problem.

\section{Acknowledgments}

This work was financed by a Fellowship from the Royal Society, which I gratefully acknowledge. I thank M. R. Dipouma, Directeur de la Chasse et de la Faune in the Ministère des Eaux et Forêts, for permission to work in the Réserve de la Lopé, and M. P. Posso, Directeur de l'Institut de Recherche en Ecologie Tropicale at Makokou. I particularly thank R. Cooper of CIRMF, M. Fernandez, N. and 228
I. Orbell, and C. Tutin for support in the field, and A. Collins, E. Rogers and C. Tutin for comments on the manuscript.

\section{References}

Gartlan, J.S. 1970. Preliminary notes on the ecology and behaviour of the drill Mandrillus leucophaeus Ritgen, 1824. In Old World Monkeys (eds J.R. Napier and P.H Napier), pp. 445-480. Academic Press, New York.

Gautier, J.P. and Gautier-Hion, A. 1969. Les associations polyspécifiques chez les Cercopithèques du Gabon. Terre et Vie, 23, 164-201.

Gautier-Hion, A. and Gautier, J.P. 1974. Les associations polyspécifiques de Cercopithèques du plateau de M'Passa (Gabon). Folia Primatol. 22, 134-177.

Grubb, P. 1973. Distribution, divergence and speciation of the drill and mandrill. Folia Primatol. 20, 161-177.

Haltenorth, T. and Diller, H. 1977. A Field Guide to the Mammals of Africa. Collins, London.

Harrison, M.J.S. 1988. A new species of guenon (genus Cercopithecus) from Gabon. J. Zool. 215, 561-575.

Harrison, M.J.S. and Hladik, C.M. 1986. Un primate granivore: le colobe noir dans la forêt du Gabon. Rev. Ecol. (Terre Vie), 41, 281-298.

Hoshino, J., Mori, A., Kudo, H. and Kawai, M. 1984. Preliminary report on the grouping of mandrills (Mandrillus sphinx) in Cameroon. Primates, 25, 295-307.

Jeannin, A. 1936. Les Mammifères Sauvages du Cameroon. Lechevalier, Paris.

Johns, A.D. and Skorupa, J.P. 1987. Responses of rainforest primates to habitat disturbance: a review. Int. J. Primatol. 8, 157-192.

Jouventin, P. 1975. Observations sur la socio-écologie du mandrill. Terre et Vie, 29, 439-532.

Kudo, H. and Mitani, M. 1985. New record of predation behaviour by the mandrill in Cameroon. Primates, 26 , 161-167.

Lahm, S.A. 1986. Diet and habitat preference of Mandrillus sphinx in Gabon: implications for foraging strategy. Am. J. Primatol. 11, 9-26.

Malbrant, R. and Maclatchy, A. 1949. Faune de l'Equateur African Français. Lechevalier, Paris.

Nicoll, M. and Langrand, O. 1986. Conservation et utilisation rationelle des ecosystèmes forestière du Gabon. WWF/ IUCN report no. 3247

Sabater Pi, J. 1972. Contribution to the ecology of Mandrillus sphinx Linnaeus 1758 of Rio Muni. Folia Primatol. 17, 304-319.

Skorupa, J.P. 1986. Responses of rainforest primates to selective logging in Kibale Forest, Uganda: a summary report. In Primates: The Road to Self-Sustaining Populations (ed. K. Benirschke), pp. 57-70. Springer-Verlag, New York.

Tutin, C.E.G. and Fernandez, M. 1984. Nationwide census of gorilla (Gorilla g.gorilla) and chimpanzee (Pan t.troglodytes) populations in Gabon. Am. J. Primatol. 6, 313-336.

Wolfheim, J.H. 1983. Primates of the World: Distribution, Abundance and Conservation. University of Washington Press, Seattle.

Michael Harrison, Department of Zoology, West Mains Road, University of Edinburgh, Edinburgh, EH9 3JT, UK.

Oryx Vol 22 No 4, October 1988 